\title{
Qualitative Assessment of the Symptoms and Impact of Pancreatic Exocrine Insufficiency (PEI) to Inform the Development of a Patient-Reported Outcome (PRO) Instrument
}

\author{
Colin D. Johnson' ${ }^{1} \cdot$ Rob Arbuckle $^{2} \cdot$ Nicola Bonner $^{2} \cdot$ Gary Connett $^{3}$ • \\ Enrique Dominguez-Munoz ${ }^{4}$ Philippe Levy ${ }^{5}$ - Doris Staab $^{6}$. \\ Nicola Williamson ${ }^{2} \cdot$ Markus M. Lerch ${ }^{7}$
}

Published online: 22 March 2017

(c) The Author(s) 2017. This article is an open access publication

\begin{abstract}
Background Pancreatic exocrine insufficiency (PEI) affects patients with chronic pancreatitis (CP) and cystic fibrosis $(\mathrm{CF})$ who produce insufficient digestive pancreatic enzymes. Common symptoms include steatorrhoea, diarrhea, and abdominal pain.

Objective The objective of the study was to develop and test the content validity of a patient-reported outcome
\end{abstract}

Nicola Williamson

nicola.williamson@adelphivalues.com

1 Department of Surgery, University of Southampton and University Hospital Southampton NHS Foundation Trust, Tremona Road, Southampton, Hampshire SO16 6YD, UK

2 Patient-Centered Outcomes, Adelphi Values, Adelphi Mill, Bollington, Cheshire SK10 5JB, UK

3 UK National Institute for Health Research Southampton Respiratory Biomedical Research Unit, Southampton Children's Hospital and University Hospital Southampton NHS Foundation Trust, Tremona Road, Southampton, Hampshire SO16 6YD, UK

4 Department of Gastroenterology, University Hospital of Santiago de Compostela, Santiago de Compostela, Spain

5 Service de Pancréatologie-Gastroentérologie, Pôle des Maladies de l'Appareil Digestif, APHP DHU UNITY, Université Denis Diderot-Paris VII Hôpital Beaujon, 92118 Clichy Cedex, France

6 Cystic Fibrosis Department, Charité University Hospital, Augustenburger Platz 1, 13353 Berlin, Germany

7 Department of Medicine A, University Medicine Greifswald, Sauerbruchstrasse, 17489 Greifswald, Germany
(PRO) instrument assessing PEI symptoms and their impact on health-related quality of life.

Methods Instrument development was supported by a literature review, expert physician interviews $(n=10$ : Germany 4, UK 3, France 3), and exploratory, qualitative, concept-elicitation interviews with patients with $\mathrm{CF}$ and CP with PEI ( $n=61$ : UK 29, Germany 18, France 14) and expert physicians $(n=10)$. Cognitive debriefing of the draft instrument was then performed with patients with PEI ( $n=37$ : UK 24, Germany 8, France 5), and feasibility was assessed with physicians $(n=3)$. For all interviews, verbatim transcripts were qualitatively analysed using thematic analysis methods and Atlas.ti computerized qualitative software. All themes were data driven rather than a priori.

Results Patient interviews elicited symptoms and impacts not reported in the literature. Six symptom concepts emerged: pain, bloating, bowel symptoms, nausea/vomiting, eating problems, and tiredness/fatigue. Six impact domains were also identified. A 45-item instrument was developed in English, French, and German for testing in cognitive debriefing patient interviews. Following cognitive debriefing, 18 items were deleted.

Conclusion Rigorous qualitative patient research and expert clinical input supported development of a PEIspecific PRO with the potential to aid management and monitoring of unmet needs among patients with PEI. The next step is to perform psychometric evaluation of the resulting instrument. 


\section{Key Points for Decision Makers}

A pancreatic exocrine insufficiency (PEI)-specific patient-reported outcome instrument has been developed on the basis of a rigorous process that included a review of the literature, patient interviews in three countries, and interviews with expert physicians.

The instrument includes assessment of symptoms (primarily gastrointestinal symptoms) and domains of physical, emotional, and social functioning.

The qualitative research was conducted in three different European countries, which should help ensure the cross-cultural validity of the instrument and ease of translation into other languages.

The instrument is being developed for use in research studies and clinical practice to aid treatment decisions and evaluation of disease severity.

\section{Introduction}

Pancreatic exocrine insufficiency (PEI) is the reduction in the synthesis and secretion of pancreatic digestive enzymes into the duodenum [1]. The most common causes of PEI are chronic pancreatitis (CP) in adults and cystic fibrosis (CF) in children/adolescents. Other causes include pancreatic tumors, acute pancreatitis, gastrointestinal surgery, and the partial or complete removal of the pancreas [2-4]. Patients with PEI resulting from any of these conditions have an increased risk of malnutrition, which is associated with increased complications, higher mortality [5], and poor survival in advanced pancreatic cancer [6].

PEI has a long subclinical course and is underdiagnosed in patients with conditions such as CP [7]. In children with $\mathrm{CF}, \mathrm{PEI}$ is usually present from infancy but can develop in later life. If untreated, PEI results in reduced nutrient absorption, leading to malnutrition-related complications such as poor growth and development and impaired immune response to infections. In patients with $\mathrm{CF}$, malnutrition is associated with respiratory morbidity and shortened survival $[8,9]$.

Steatorrhoea (fatty stools) is the defining PEI symptom. However, patients may also experience diarrhea, weight loss, vitamin deficiency symptoms, abdominal distension, and flatulence [5], which can adversely impact patients' health-related quality of life (HRQoL) and survival $[10,11]$. In Europe and the USA, patients diagnosed with PEI are treated with pancreatic enzyme-replacement therapy (PERT), but many are undiagnosed or under-treated $[12,13]$. To avoid malnutrition-related morbidity and mortality in patients with $\mathrm{CP}$, PERT should commence as soon as PEI is diagnosed [14]. Lack of diagnosis and under-treatment intensify the symptom experience and may increase the impact on HRQoL [10, 11].

Given the subjective nature of PEI symptoms (e.g., abdominal pain and diarrhea), a patient-reported outcome (PRO) instrument that collects information directly from the patient about symptom severity and impacts could be of value in clinical practice to inform treatment decisions and aid tracking of disease severity [15-17]. The development of any PRO should start with rigorous qualitative research in the target patient population combined with expert physician input to ensure that all concepts that are important and relevant to patients are included [15]. It is then crucial that items, response scales, and recall periods are worded simply enough that they are interpreted and understood consistently and as intended. A PRO measure for use in PEI (PEI-Q) could provide physicians with valuable information about patients' symptoms and impacts on their HRQoL that may not emerge organically during all clinical interviews. For example, insomnia and fatigue are reported by most patients with $\mathrm{CP}[10,11]$ but are rarely discussed in clinical interviews.

The objective of this study was to follow best practice methods for PRO instrument development and validation to develop a PRO instrument to assess all PEI symptoms and the associated impact on HRQoL for use in clinical practice $[16,18]$. Such a PRO instrument may also be useful when assessing symptoms in studies and randomized trials of PEI treatments. Specific objectives were to identify key symptoms and impacts reported by patients with PEI and $\mathrm{CP}$ or $\mathrm{CF}$, physicians, and published literature and to use concepts elicited by patients to develop a PRO instrument to assess PEI symptoms and impacts.

\section{Materials and Methods}

The PEI instrument was developed in six key stages (Fig. 1).

\subsection{Literature and Patient-Reported Outcomes Instrument Review}

A targeted peer-reviewed literature search was conducted in the PubMed, PsycINFO, and EMBASE databases to identify qualitative research articles outlining patient-reported PEI symptom and impact concepts. Searches were conducted using disease and qualitative research search terms (Table 1) yielding 100 abstracts, six of which met inclusion criteria and were reviewed in full. Symptom and impact concepts identified from the articles informed the development of a preliminary PEI conceptual model. 


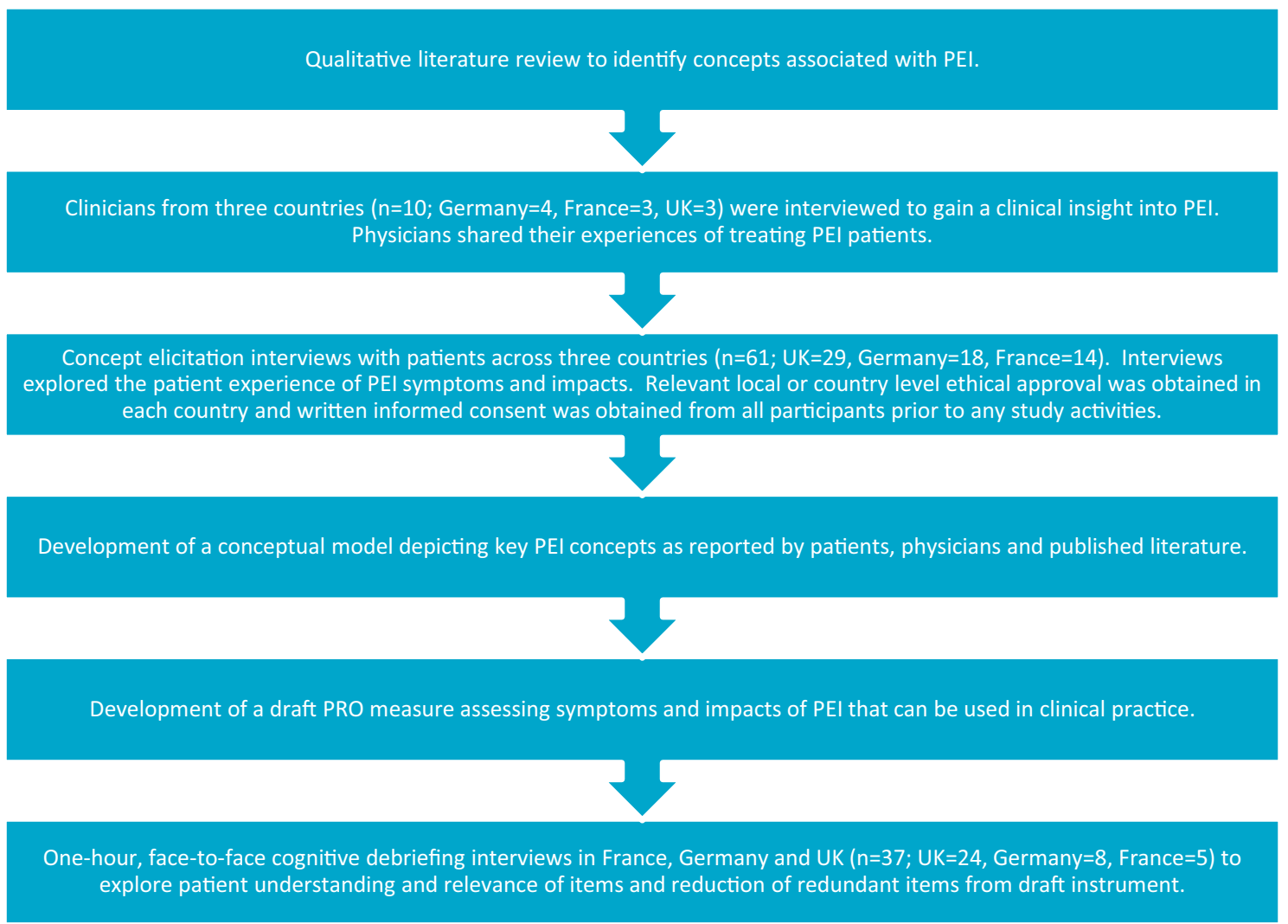

Fig. 1 Overview of pancreatic exocrine insufficiency-specific patient-reported outcome development process. $P E I$ pancreatic exocrine insufficiency, $P R O$ patient-reported outcome

Table 1 Qualitative literature review search strategy

\begin{tabular}{|c|c|}
\hline Search type & Search terms \\
\hline Disease-related terms & $\begin{array}{l}\text { Pancreatitis, cystic fibrosis AND pancreas OR pancreatic insufficiency, pancreatic cancer, pancreas AND disease, } \\
\text { pancreatic exocrine insufficiency OR PEI OR exocrine pancreatic insufficiency OR EPI, pancreas AND surgery OR } \\
\text { pancreatectomy OR gastrectomy }\end{array}$ \\
\hline $\begin{array}{l}\text { Qualitative research } \\
\text { terms }\end{array}$ & $\begin{array}{l}\text { Qualitative OR phenomenology OR grounded theory OR thematic analysis OR narrative OR focus group OR interview } \\
\text { OR subjective experience OR patient experience OR lived experience }\end{array}$ \\
\hline
\end{tabular}

$E P I$ exocrine pancreatic insufficiency, $P E I$ pancreatic exocrine insufficiency

A review of 1520 abstracts identified six existing PRO instruments that have been used in PEI for full review: the European Organisation for Research and Treatment of Cancer core questionnaire [19], the European Organisation for Research and Treatment of Cancer pancreatic cancer questionnaire [20], the Digestive Diseases Questionnaire [21], the Functional Assessment of Cancer Therapy Hepatobiliary Symptom Index [22], the Gastrointestinal Symptom Rating Scale [23], and the Gastrointestinal Quality of Life Index [24]. However, none of the instruments reviewed had adequate evidence of content validity and psychometric validity in PEI as none had been specifically developed or validated in a PEI population.

\subsection{Physician Interviews}

Open-ended qualitative telephone interviews were conducted with ten $\mathrm{CF}$ and $\mathrm{CP}$ expert physicians in Germany $(n=4)$, France $(n=3)$ and the UK $(n=3)$ to provide insight into the most important and relevant PEI concepts from a clinical perspective. Findings informed revisions to the conceptual model.

\subsection{Concept-Elicitation Patient Interviews}

Semi-structured qualitative concept-elicitation interviews of 1-h in duration ( $n=61$ : UK 29, Germany 18, France 14) 
were conducted with adult patients with PEI (aged $\geq 18$ years and diagnosed with either $\mathrm{CP}$ or $\mathrm{CF}$ ) in France, Germany, and the UK and adolescent patients with $\mathrm{CF}$ (aged 12-17 years) in the UK. In the UK, all interviews were conducted face-to-face either at the participant's home or at the clinical site. In France and Germany, all interviews were conducted remotely via telephone. Participants were mostly interviewed on their own, but if a family member was present they were asked not to partake in or contribute to the interview. The qualitative sample size was determined based on an aim to include a sample sufficient to be likely to achieve 'conceptual saturation' (the point when no new concepts emerge from patient interviews) [25, 26]. Others have suggested that, in a relatively homogenous population, a sample of 12 patients can be sufficient to achieve conceptual saturation $[25,26]$. With that in mind, a minimum sample of at least 12 in each country was targeted, such that the total sample (and also the total CF and CP samples) would be considerably larger. Conceptual saturation was assessed for the whole sample and by condition and country; patients were ordered according to date of interview and split into three groups. The concepts elicited in each group were compared. Conceptual saturation was continually evaluated in parallel with interviews, and interviews were conducted until saturation was achieved; saturation was considered to be achieved if no new concepts were elicited in the third group of patients. A purposive approach to sampling with the inclusion of recruitment quotas was also used to ensure the concept-elicitation sample included patients with a range of demographic characteristics, including age, sex, education level, and disease condition.

Eligible patients had to have a physician-confirmed diagnosis of PEI and either CP or CF. Patients with CP had to have been treated for $\leq 10$ years, and both patients with $\mathrm{CP}$ and those with $\mathrm{CF}$ had to have experienced PEI symptoms in the year prior to recruitment. All patients were required to be literate in French, German, or English and willing to participate in a 1-h interview. The following patients were excluded: those with ileus/bowel obstruction, acute abdomen, malignancy involving the digestive system, coeliac disease, or Crohn's disease; those who had undergone solid organ transplant or surgery affecting the large or small bowel or for isolated gastrectomy; and patients with $\mathrm{CF}$ with a history of fibrosing colonopathy.

Participants were identified by their physician using a purposive sampling methodology whereby participants who met the inclusion criteria and had an upcoming clinical appointment were invited to participate. In all countries, participants were invited to participate in the study by their physician during a routine face-to-face appointment. They were provided with a study letter providing information about the study aims and goals, and written informed consent was obtained prior to commencement of study-related activities. Participants had no known preexisting relationship with or knowledge about the interviewers. Prior to each interview, the interviewer informed participants about the purpose of doing the interviews and the interviewer's involvement in the research. No record of refusal to participate was recorded for the study, and no participants withdrew from the study after agreeing to participate.

A semi-structured interview guide was developed with expert clinical input and included concepts identified from the literature review to ensure questions and prompts were appropriate to participants. Interviews were conducted by a team of experienced qualitative interviewers (N. Williamson, C. Tolley, and L. Maguire in the UK; Caroline Jonquet in France; Sabine Bielfeldt in Germany) who represented different age groups to minimize interviewer bias. Additionally, interviewers had limited knowledge of the disease area, maximizing spontaneous elicitation of information of importance to the participant without potential bias. Interviews started with open-ended questions and were followed with more direct questions to allow for spontaneous discussion concerning PEI symptoms, impact, treatments, and coping strategies while ensuring all important topics were covered if they did not emerge spontaneously. Field notes were taken during the interviews to ensure all topics were covered and to document any notable non-verbal behaviors of participants that should be considered when interpreting the results. All interviews were audio-recorded, transcribed verbatim, and translated into English where relevant. Transcripts were quality checked by the interviewer who conducted the interview to ensure consistency and accuracy in transcription prior to analysis; however, transcripts were not returned to participants for comment because of project time restraints. Qualitative analysis was performed using Atlas.ti software, which involved grouping of quotes into themes using thematic analysis methods [27]. All themes identified were driven by data rather than a priori assumptions. A coding tree was developed prior to analysis of any interviews to structure how concepts and sub-concepts would be coded. The coding tree was used consistently to guide coding of all the interviews (Fig. 2). A team of three experienced qualitative data coders (N. Williamson, L. Maguire, and C. Tolley) coded the transcripts in parallel using a constant comparative method, and all coding was overseen by the project lead (N. Bonner) to ensure codes were consistently applied.

Ethical approval was obtained in the UK (National Research Ethics Service reference: 12/YH/0500) and Germany (Universitätsmedizin Greifswald Ethikkommision reference: BB 123/12). A waiver was granted in France (reference: AV128200A). 


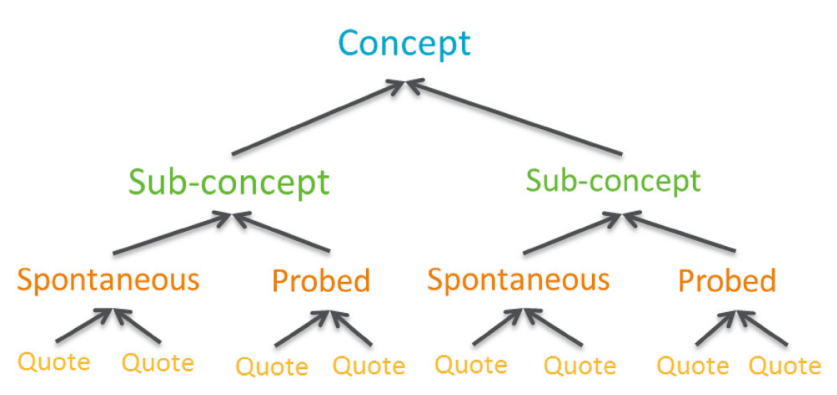

Fig. 2 Example coding tree

\subsection{PRO Instrument Development}

Items were simultaneously developed in British English, French, and German with expert linguistic and clinical input. They were developed using verbatim content from the interviews and worded using patient language to be comprehensible to all education levels while considering conceptual relevance across languages/cultures. The linguistic expert helped ensure linguistic and cultural equivalence of the formulations across the language versions and that the items developed would be relatively easy to translate into other languages in the future.

\subsection{Cognitive Debriefing Patient Interviews}

Content validity of the PRO was evaluated through cognitive debriefing interviews with 37 adult patients with $\mathrm{CF}$ or CP [28] in the UK $(n=16)$, Germany $(n=8)$, and France $(n=5)$ as well as adolescents in the UK $(n=8)$. Patients were identified and recruited through their physician using the same recruitment process as for the conceptelicitation interviews. Although no formal sample size was calculated, recruitment quotas were adopted to ensure the sample effectively represented different demographic characteristics, including age, sex, education, and disease condition. This ensured that any heterogeneity in the population and likely responses was captured, and the PEIQ was tested in patients who were representative of the target population, including participants who may have difficulty interpreting or completing the PRO [29, 30]. Inclusion and exclusion criteria were the same as for the concept-elicitation interviews except that participation in the concept-elicitation stage was an exclusion criterion. As in concept elicitation, participants were approached by their physician and invited to participate, and written informed consent form was obtained prior to commencement of study-related activities. Interviews in both stages were therefore one-off interviews scheduled with individual patients. Patients completed the 45-item questionnaire using a 'think-aloud' method and were asked detailed debriefing questions to evaluate their understanding and the relevance of questions to their PEI experience [28]. Qualitative analysis of verbatim transcripts was performed and results used to inform modification or deletion of items, although the earlier concept-elicitation findings and expert clinical input were also taken into account.

\section{Results}

\subsection{Literature Review}

The literature search identified key symptoms (including painful gastrointestinal sensations, other gastrointestinal sensations, trapped wind, changes in appearance of stools, changes in bowel movements, eating-related symptoms) and impact concepts (including psychological, family, occupational, eating-related, tiredness/fatigue, loss of physical strength, and PEI treatment impacts). Additionally, coping concepts (e.g., altering administration of enzymes, denial, socializing with people who know about the condition, relying on others for support, balancing benefits and risk, modifying diet, and performing upright gentle activities) and triggers (e.g., eating-related) associated with patients' PEI experience were also elicited (Table 2).

\subsection{Physician Interviews}

All physician interviews were conducted between July and October 2012. The PEI symptoms most commonly reported by $\mathrm{CF}$ and $\mathrm{CP}$ physicians were weight loss (considered highly important by the physicians interviewed, but not identified in the literature review), abdominal pain, diarrhea, and fatty stools (all reported by six physicians each). The physicians suggested that diet $(n=10)$ and, to a lesser extent, social functioning $(n=3)$ were the HRQoL domains most impacted by PEI. Physicians specializing in CF reported fewer PEI symptom and impact concepts than those specializing in CP. Additionally, the physicians mentioned problems with treatment adherence $(n=4)$, particularly among children and adolescents, who may miss medication to avoid taking treatment in front of peers, and among adult patients with $\mathrm{CP}$ who continue to consume alcohol.

\subsection{Concept-Elicitation Patient Interviews}

A total of 61 concept-elicitation interviews were conducted with patients with $\mathrm{CF}$ or $\mathrm{CP}$ between October 2012 and September 2013. Table 3 summarizes the numbers of patients interviewed in each diagnosis group in each country. 
Table 2 Pancreatic exocrine insufficiency concepts elicited from qualitative literature review

\begin{tabular}{ll}
\hline Concept & Sub-concepts identified \\
\hline Symptoms & $\begin{array}{c}\text { Painful gastrointestinal sensations, other gastrointestinal sensations, trapped wind, changes in appearance of stools, changes in } \\
\text { bowel movements, symptoms related to eating }\end{array}$ \\
Impacts & Psychological, family, occupational, and eating-related impacts; fatigue/tiredness/lack of energy; loss of physical strength; and \\
& PEI treatment-related impacts \\
Coping & Altering administration of enzymes, denial, socializing with people who know about the condition, relying on others for \\
strategies & support, balancing benefits and risk, modifying diet, and performing upright gentle activities \\
Triggers & Eating-related
\end{tabular}

$P E I$ pancreatic exocrine insufficiency

Table 3 Diagnosis of patients interviewed at the concept-elicitation stage by country

\begin{tabular}{lclcc}
\hline Country & Adult CF & Adolescent CF & Adult CP & Total \\
\hline France & 6 & 0 & 8 & 14 \\
Germany & 9 & 0 & 9 & 18 \\
UK & 12 & 9 & 8 & 29 \\
Total & 27 & 9 & 25 & 61 \\
\hline
\end{tabular}

$C F$ cystic fibrosis, $C P$ chronic pancreatitis

\subsection{Demographic and Clinical Characteristics}

The sample was evenly distributed in terms of sex (32 males, 29 females), and the mean age was 36 years (range 12-81). Steatorrhoea was the most common symptom leading to diagnosis of PEI across all conditions; however, most patients were diagnosed using multiple methods (Table 4). Unsurprisingly, adult patients with $\mathrm{CF}$ had a longer mean time since diagnosis (26 years) and more years receiving medication ( 25 years) than adults with $\mathrm{CP}$ (5 and 4 years, respectively) and adolescents with CF (11 and 13 years, respectively).

\subsection{Symptoms}

Six primary symptom concepts were elicited from the patient interviews: pain, bloating symptoms, bowel movements, nausea/vomiting, eating-related symptoms, and tiredness/fatigue. Table 5 presents the sub-concepts and example quotes, and details of findings are provided in the following sections.

\subsubsection{Pain}

In total, 49 (80\%) patients reported experiencing pain; 51 (84\%) reported experiencing abdominal pain, 49 (96\%) of them spontaneously. Of those, 40 (78\%) described abdominal pain occurring mostly in their stomach; patients with CF most often reported pain in the upper and lower abdominal quadrants, whereas patients with CP more often reported upper-right abdominal pain. Both patients with $\mathrm{CF}$ and those with $\mathrm{CP}$ also reported non-abdominal pain, but whether that pain should be attributed to PEI or comorbid conditions was unclear; no adolescents with $\mathrm{CF}$ reported non-abdominal pain.

\subsubsection{Bloating Symptoms}

Bloating or other gas-related abdominal symptoms were reported by $39(64 \%)$ patients; $50(82 \%)$ patients reported stomach noises, $20(33 \%)$ reported high levels of flatulence, and nine $(15 \%)$ reported "trapped wind".

\subsubsection{Bowel Movement/Stool Symptoms}

Patients described several bowel movement-related symptoms; 29 (48\%) experienced constipation (although it is recognized that may be due to treatment-related side effects), 11 (18\%) increased frequency of bowel movements, and $20(33 \%)$ bowel urgency. In total, $46(75 \%)$ patients experienced diarrhea, 30 (49\%) passed fatty stools, a key PEI symptom, and $31(51 \%)$ described a change in stool color associated with PEI, e.g., passing more 'light colored' ( $n=15$ [48\%]), 'yellow/brown' $(n=15$ [48\%]), and 'orange' $(n=10$ [32\%]) stools; $13(42 \%)$ described stools having an unusual or strong odor.

\subsubsection{Nausea and Vomiting}

Nausea and vomiting symptoms were reported by 39 (64\%) patients, with 17 (44\%) reporting experiencing nausea only, eight (21\%) vomiting only, and eight (21\%) both nausea and vomiting.

\subsubsection{Eating-Related Symptoms}

Patients had experienced weight loss $(n=41$ [67\%]) and loss of appetite $(n=20$ [33\%]). More adults with CP 
Table 4 Demographic and clinical characteristics of the concept-elicitation sample $\left(N_{\text {tot }}=61\right)$

\begin{tabular}{|c|c|c|c|c|}
\hline & Adult $\mathrm{CV}(N=27)$ & Adult $\mathrm{CP}(N=25)$ & Adolescent $\mathrm{CF}(N=9)$ & Total $(N=61)$ \\
\hline \multicolumn{5}{|l|}{ Patient-reported } \\
\hline \multicolumn{5}{|l|}{ Sex } \\
\hline Male & $11(41)$ & $16(64)$ & $5(56)$ & $32(52)$ \\
\hline Female & $16(59)$ & $9(36)$ & $4(44)$ & $29(48)$ \\
\hline \multicolumn{5}{|l|}{ Age } \\
\hline Mean & 30 & 52 & 14 & 36 \\
\hline Minimum, maximum & 19,64 & 20,81 & 12,16 & 12,81 \\
\hline Missing data & 0 & $1(4)$ & 0 & $1(2)$ \\
\hline Ethnicity & $N=21^{\mathrm{a}}$ & $N=17^{\mathrm{a}}$ & & $N=47$ \\
\hline White/Caucasian & $18(86)$ & $16(94)$ & $9(100)$ & $43(91)$ \\
\hline African, Caribbean, or Black & 0 & 0 & 0 & 0 \\
\hline Asian & $2(10)$ & $1(6)$ & 0 & $3(6)$ \\
\hline Mixed race & $1(5)$ & 0 & 0 & $1(2)$ \\
\hline Adults only-education & & & & $N=52$ \\
\hline Some high school, but no diploma or GED & $3(11)$ & $5(20)$ & NA & $8(15)$ \\
\hline High school diploma or equivalent & $4(15)$ & $5(20)$ & & $9(17)$ \\
\hline Some college or associate's degree/bachelor's degree & $10(37)$ & $6(24)$ & & $16(31)$ \\
\hline Some graduate work & $4(15)$ & $2(8)$ & & $6(12)$ \\
\hline Post-graduate degree & $3(11)$ & $5(20)$ & & $8(15)$ \\
\hline GCSE & $1(4)$ & 0 & & $1(2)$ \\
\hline GCE A level & $1(4)$ & 0 & & $1(2)$ \\
\hline CIMA (accountant) & 0 & $1(4)$ & & $1(2)$ \\
\hline $\mathrm{PhD}$ & $1(4)$ & 0 & & $1(2)$ \\
\hline National Craftsman Certificate & 0 & $1(4)$ & & $1(2)$ \\
\hline \multicolumn{5}{|l|}{ Physician-reported } \\
\hline \multicolumn{5}{|l|}{ How PEI was diagnosed } \\
\hline Weight loss & 0 & $10(40)$ & $2(22)$ & $12(20)$ \\
\hline Steatorrhea & $19(70)$ & $17(68)$ & $5(56)$ & $41(67)$ \\
\hline Diarrhea & $4(15)$ & $15(60)$ & $4(44)$ & $23(38)$ \\
\hline Bloating & $5(19)$ & $12(48)$ & $2(22)$ & $19(31)$ \\
\hline Abdominal discomfort & $7(26)$ & $16(64)$ & $4(44)$ & $27(44)$ \\
\hline Fecal elastase test & $7(26)$ & $12(48)$ & $9(100)$ & $28(46)$ \\
\hline Recurrent rectal prolapse & $1(4)$ & 0 & 0 & $1(2)$ \\
\hline Meconium level & $1(4)$ & 0 & 0 & $1(2)$ \\
\hline Neonatal screening & $2(7)$ & 0 & 0 & $2(3)$ \\
\hline Failure to thrive & $1(4)$ & 0 & 0 & $1(2)$ \\
\hline Missing data & $2(7)$ & 0 & 0 & $2(3)$ \\
\hline \multicolumn{5}{|l|}{ Years since diagnosis } \\
\hline Mean & 26 & 5 & 11 & 16 \\
\hline Minimum, maximum & 13,48 & 0,23 & 3,16 & 0,48 \\
\hline Missing data & $2(7)$ & $3(12)$ & 0 & $5(8)$ \\
\hline \multicolumn{5}{|l|}{ Years receiving PEI medication } \\
\hline Mean & 25 & 4 & 13 & 15 \\
\hline Minimum, maximum & 3,47 & 0,9 & 11,16 & 0,47 \\
\hline Missing data & $1(4)$ & 0 & 0 & 1 \\
\hline
\end{tabular}

Data are presented as $n(\%)$ unless otherwise indicated

$C F$ cystic fibrosis, $C I M A$ Chartered Institute of Management Accountants, $C P$ chronic pancreatitis, GED General Educational Development, $G C E$ General Certificate of Education, GCSE General Certificate of Secondary Education, NA not applicable, $N_{\text {tot }}$ number in total sample, PEI pancreatic exocrine insufficiency

${ }^{a}$ Data protection rules precluded patient ethnicity being collected in France 
Table 5 Pancreatic exocrine insufficiency conceptual framework

\begin{tabular}{|c|c|c|}
\hline Concepts & Sub-concepts & Example quote from qualitative patient research [condition, sex, age (years)] \\
\hline \multicolumn{3}{|l|}{ PEI symptoms } \\
\hline \multirow[t]{2}{*}{ Pain } & Abdominal pain & "Well, it's like having a knife being rammed in" (CF, female, 24) \\
\hline & Non-abdominal pain & $\begin{array}{l}\text { "The only way I can describe that is like having toothache in your back on both sides ..., } \\
\text { which goes, vertically up your back" (CP, male, } 60)\end{array}$ \\
\hline \multirow[t]{5}{*}{ Bloating symptoms } & Bloating & $\begin{array}{l}\text { "It's a strange feeling, as if I've ate too much and I haven't had anything to eat at all" (CP, } \\
\text { male, 55) }\end{array}$ \\
\hline & Distension & $\begin{array}{l}\text { "It hurts and it also doesn't look very attractive because it makes you a bit fat" (CF, female, } \\
22)\end{array}$ \\
\hline & Bowel noises & "It sounded like a washing machine, it would start to grumble like crazy" (CF, female, 22) \\
\hline & Flatulence & $\begin{array}{l}\text { "Sometimes, I was like sitting on the toilet, and it would just be wind that would be coming } \\
\text { out" (CF, female, 40) }\end{array}$ \\
\hline & Trapped wind & "You can feel that it's filling up a ... a gas ... in your stomach and your guts" $(\mathrm{CP}$, male, 55$)$ \\
\hline \multirow{9}{*}{$\begin{array}{l}\text { Bowel movement/ } \\
\text { stool symptoms }\end{array}$} & Constipation & "I would no longer go to have bowel movements ... it just didn’t come." (CP, male, 68) \\
\hline & $\begin{array}{l}\text { Frequency of bowel } \\
\text { movements }\end{array}$ & "If it's really bad, four or five times a day." (CP, female, 29) \\
\hline & Diarrhea & $\begin{array}{l}\text { "You'd be working in someone's garden, and you'd have diarrhea, and you can't really use } \\
\text { their toilet ..." (CF, male, 47) }\end{array}$ \\
\hline & Pain in the bottom & $\begin{array}{l}\text { "I would have thought it's more like - say like if you're having trouble going to the toilet, } \\
\text { more like straining and trying to like go, rather than it just going normally." (CF, female, 25) }\end{array}$ \\
\hline & Stool appearance & $\begin{array}{l}\text { "Often it is very varied } \ldots \text { the diarrhea is actually always orange } \ldots \text { There are brownish to } \\
\text { black spots in it." (CP, male, 54) }\end{array}$ \\
\hline & Bowel urgency & $\begin{array}{l}\text { "It happens quite often, so that I have to plan that I know if I am outside my apartment, there is } \\
\text { a toilet close by." (CF, female, 51) }\end{array}$ \\
\hline & Stool color & $\begin{array}{l}\text { "It varies depending on what I eat ... it is usually a weird yellowish brown. But oddly, when I } \\
\text { have fatty stools, then it's as if oil is coming out with it and then it is usually always red." } \\
(\mathrm{CF}, \text { female, } 21)\end{array}$ \\
\hline & Stool smell & "It just really smells. Just it’s ... uh, for me, it smells like baby poo" (CF, female, 34$)$ \\
\hline & Fatty stools & "This oily, fatty feces always sticks to the toilet ..." (CP, male, 55) \\
\hline \multirow[t]{2}{*}{ Nausea/vomiting } & Nausea & "Really it's just, you know, feeling like you need to be sick or ... but not." (CF, male 32 ) \\
\hline & Vomiting & $\begin{array}{l}\text { "One of the major blockages that } \mathrm{I} \text { had, I was actually ... I was actually vomiting with that } \\
\text {..." (CF, female, } 34)\end{array}$ \\
\hline \multirow[t]{2}{*}{ Eating } & Loss of appetite & $\begin{array}{l}\text { "When digestion still hasn't happened, you get the feeling ... No, no, you really get the feeling } \\
\text { that you have been eating for three weeks straight, and then you're really not hungry any } \\
\text { longer" (CF, male, 28) }\end{array}$ \\
\hline & Weight loss & "I lost about two stone. I went down to nine stone and I looked terrible" (CP, male, 55) \\
\hline Tiredness & Tiredness & "Well I can go to work. Yeah, but I get tired and exhausted." (CP, female, 29) \\
\hline \multicolumn{3}{|l|}{ PEI impacts } \\
\hline \multirow[t]{4}{*}{$\begin{array}{l}\text { Impact on daily } \\
\text { activities }\end{array}$} & Daily activities & $\begin{array}{l}\text { "When I do have a bad day then it has an extreme effect, where I just can't do anything or I am } \\
\text { limited in what I can do or I simply cannot do anything else." (CF, male, 24) }\end{array}$ \\
\hline & Physical activities & $\begin{array}{l}\text { "If I've got a stomachache, I find, um, like running around a bit more difficult, but nothing } \\
\text { hugely." (CF, male, 12) }\end{array}$ \\
\hline & Concentration & $\begin{array}{l}\text { "I can't concentrate on things. I can keep my mind off things if I'm doing something that } \\
\text { doesn't take any concentration. Which is like watching the telly or something." (CF, male, } \\
\text { 16) }\end{array}$ \\
\hline & Proximity to toilet & "If I wasn't taking my tablets, I would be like on the toilet $24 / 7 . "(\mathrm{CF}$, female, 15) \\
\hline
\end{tabular}


Table 5 continued

\begin{tabular}{|c|c|c|}
\hline Concepts & Sub-concepts & Example quote from qualitative patient research [condition, sex, age (years)] \\
\hline \multirow[t]{4}{*}{$\begin{array}{l}\text { Impact on emotional } \\
\text { wellbeing }\end{array}$} & Embarrassment & $\begin{array}{l}\text { "I clasp my hands together over my head and just have to let it out, because that also causes } \\
\text { the cramps, then it's quite embarrassing, when I have to go to the toilet there." (CF, female, } \\
\text { 21) }\end{array}$ \\
\hline & Frustration & $\begin{array}{l}\text { "Sometimes I couldn't even get to my check-up appointments here or to my doctor's office } \\
\text { consultations in the morning because I just never came down from the toilet and that was } \\
\text { always the most frustrating thing to me." (CF, female, 22) }\end{array}$ \\
\hline & Worry/anxiety/stress & $\begin{array}{l}\text { "I am always worried that something is going to happen, that the ducts become obstructed } \\
\text { again." (CP, female, 75) }\end{array}$ \\
\hline & Sadness & $\begin{array}{l}\text { "Sometimes if I want to do something and can't because my stomach hurts, then I'll be sad." } \\
(\mathrm{CF}, \text { female, 12) }\end{array}$ \\
\hline \multirow[t]{3}{*}{ Impact on diet } & Diet awareness & $\begin{array}{l}\text { "I mean the thing ... I'm eating ... I've been doing this whole diet ... the whole [inaudible] } \\
\text { dietary management thing since I was like six, so you sort of know in your head, you're } \\
\text { supposed to go for the high-calorie stuff." (CF, male, 22) }\end{array}$ \\
\hline & $\begin{array}{l}\text { Managing } \\
\text { medication }\end{array}$ & $\begin{array}{l}\text { "If you don't [take] the right amount of Creon, or if you forget the Creon, it's kind of } \\
\text { embarrassing, but you're just like on the toilet after that." (CF, female, 26) }\end{array}$ \\
\hline & Avoiding fatty food & "Also mindful about eating fatty food and cutting fat off and that sort of stuff." (CP, male, 60) \\
\hline \multirow[t]{5}{*}{$\begin{array}{l}\text { Impact on social } \\
\text { functioning }\end{array}$} & Social activities & $\begin{array}{l}\text { "You have to postpone what you've planned because you don't know how it's going to } \\
\text { continue and how the day or next few hours will go, depending on how bad it is." (CP, male, } \\
24)\end{array}$ \\
\hline & $\begin{array}{l}\text { Relationship with } \\
\text { friends }\end{array}$ & $\begin{array}{l}\text { "When I was younger, I had different friends. Perhaps we'd run around at breaks. Obviously, } \\
\text { if I had a stomachache, I perhaps wouldn't run around as much." (CF, male, 12) }\end{array}$ \\
\hline & Staying at home & $\begin{array}{l}\text { "The best thing to do is stay home and somewhere that's comfortable, where there's a toilet, } \\
\text { and you can sit there in peace and wait as long as it takes." (CF, male, 24) }\end{array}$ \\
\hline & Family & $\begin{array}{l}\text { "My parents had to cope with always running after me, giving me tablets and nagging me } \\
\text { when I didn't take them, and despite that, they were there for me when I hadn't taken them } \\
\text { and I was suffering." (CF, female, 22) }\end{array}$ \\
\hline & Intimate relations & $\begin{array}{l}\text { "It is always a bit strained anyway. Look, first he has to look first if I ... we can't say yet, } \\
\text { "Now, tomorrow we're going to get up at 5", and I always have to get up earlier, because I } \\
\text { need at least an hour to deal with the sugar, inhalation, physio and I have to do a little bit." } \\
(\mathrm{CF}, \text { female, 24) }\end{array}$ \\
\hline \multirow[t]{2}{*}{$\begin{array}{l}\text { Impact on work or } \\
\text { study }\end{array}$} & $\begin{array}{l}\text { Time missed at } \\
\text { work/study }\end{array}$ & "I was absent, missing work hours because I was constantly tired." (CP, male, 60) \\
\hline & $\begin{array}{l}\text { Performance at } \\
\text { work/study }\end{array}$ & $\begin{array}{l}\text { "Physically while working, it still shows somehow that this here ... at least I imagine it, that } \\
\text { there is something that inhibits me a little. When I work in a bent over position or something } \\
\text { like that. I want to say I'm not as efficient." (CP, male, 62) }\end{array}$ \\
\hline Sleep & Sleep & "If digestion goes badly, then you sleep poorly afterward." (CF, female, 32) \\
\hline
\end{tabular}

$C F$ cystic fibrosis, $C P$ chronic pancreatitis, $P E I$ pancreatic exocrine insufficiency, $p t$ patient

reported weight loss $(n=22[54 \%])$ and lack of appetite $(n=10[24 \%])$ than adults with $\mathrm{CF}(n=6[15 \%])$ and adolescent patients $(n=4[10 \%])$.

\subsubsection{Tiredness}

In total, $25(41 \%)$ patients reported experiencing tiredness but did not specifically associate this with PEI.

\subsection{Impact}

More HRQoL impact concepts were reported in the patient interviews than in the literature or from physicians. The six reported HRQoL impact concepts were grouped into the domains daily activities, emotional, dietary, social, family and relationships, work, and school. The most common daily activities impacted were 'housework,' 'holidays,' and 'travelling' (all $n=6$ [10\%]). In terms of emotional impacts, patients commonly reported being embarrassed by their symptoms (particularly bowel symptoms; $n=22$ [36\%]). A large proportion of patients described having to avoid fatty foods ( $n=23$ [38\%]), or other dietary restrictions. Finally, a large proportion of patients described avoiding going out $(n=19$ [31\%]) and their relationships with friends being impacted by their PEI ( $n=17$ [28\%]). Over half of the sample $(n=33$ [54\%]) described their work and/or schoolwork being impacted by their PEI.

Patients also discussed symptom trigger sub-concepts, most commonly eating fatty foods ( $n=25$ [41\%]), eating the wrong food ( $n=20[33 \%])$, and stress related to eating 
$(n=11[18 \%])$. Patients also described coping strategies such as lying down $(n=13$ [21\%]), avoiding eating $(n=11[18 \%])$, and applying heat to the abdomen $(n=9$ [15\%]).

Conceptual saturation was achieved within all samples analysed, with no new symptom or impact concepts emerging from the last group of interviews analysed.

\subsection{Management of Pancreatic Exocrine Insufficiency Medication}

Patients described difficulties estimating PEI medication dosage for food consumed, and commonly reported difficulties with medication adherence, including forgetting to take or taking too much medication, resulting in diarrhea, lighter/orange stools ( $n=6$ [10\%] for each), constipation $(n=5[8 \%])$, fatty/oily stools $(n=3[5 \%])$, abdominal discomfort, gas ( $n=2$ [3\%] for each), weight loss, changes in stool color, needing to be close to a toilet, and impact on relationships ( $n=1$ [2\%] for each).

\subsection{Conceptual Model}

Figure 3 presents the conceptual model for all concepts that were derived from the literature review and physicians and the patient concept-elicitation interviews. Following analysis of all interviews, the developed conceptual model was shared with expert $\mathrm{CF}$ and $\mathrm{CP}$ physicians practicing in the UK $(n=3)$, France $(n=2)$, and Germany $(n=2)$, who verified the relevance of concepts. These clinical experts noted that evidence from the patient interviews was consistent with their experience but also extended their understanding of the patient experience and impact of PEI on HRQoL. The sub-concepts that assess different aspects of these relatively broad concepts are detailed in the conceptual framework in Table 5. For example, symptom is a concept and abdominal pain is a specific type (sub-concept) of symptom.

\subsection{PRO Instrument Development}

A draft 45-item PEI-specific PRO instrument, the PEI-Q, was developed based on the above conceptual model, patient interview findings, and clinical input. Example symptom and impact items included in the PEI-Q are shown in Fig. 4. Separate symptom and impact conceptual frameworks for the instrument are presented in Table 5.

\subsection{Cognitive Debriefing Patient Interviews}

The relevance and patient understanding and interpretation of the items included in the draft instrument was evaluated through cognitive debriefing interviews $(n=37)$ conducted in the UK $(n=24)$, Germany $(n=8)$, and France $(n=5)$ between March and September 2014. Target samples were achieved in Germany and the UK; however, recruitment was below target in France. Physician input was sought on proposed deletions to ensure key PEI symptoms and impacts were retained. Discussions between the researchers, study sponsor, and expert physicians were held at each stage of the decision-making process until consensus was reached. Items were removed that were either not strongly relevant to patients' PEI experience or overlapped with other concepts. Specifically, ten items were deleted as they were not considered specific to PEI or were relevant to a small proportion of participants: constipation; vomiting; pain in bottom; tiredness; stomach noises; feeling down; and impact on family life, relationship with partner, work/school, and performance at work. Eight items were also considered to overlap conceptually with other items and thus were deleted: stomach looking big and round (overlapped with bloating), trapped wind (overlapped with bloating), needing to go to the toilet (overlapped with average bowel movements), impact on sports/exercise (overlapped with daily activities), and relationship with friends (overlapped with social activities). The instrument was reduced to 27 items.

\section{Discussion}

This paper describes the development of the first known PEI-specific PRO instrument, developed on the basis of indepth and rigorous qualitative research. The instrument has been developed with the goal of providing patients and physicians with more comprehensive and systematically collected information about PEI patients' symptoms and HRQoL functioning to aid patient-physician communication and management of PEI. The qualitative interviews with both patients with $\mathrm{CP}$ and those with $\mathrm{CF}$ and with physicians identified many patient-reported concepts relevant to capturing the full range of PEI symptoms and impacts on patients' daily lives [15, 31]. Many of these concepts have not previously been documented in the literature, highlighting the value of collecting data directly from patients to fully understand their experience of symptoms and impacts. During the qualitative interviews, physicians specializing in CF reported fewer PEI symptom and impact concepts than those specializing in CP. This may reflect that patients with $\mathrm{CF}$ have usually been receiving treatment for longer than those with $\mathrm{CP}$ and have usually experienced symptoms since childhood, reducing the impact. It may also be the case that certain symptoms are features of $\mathrm{CP}$ and not of $\mathrm{CF}$. Set against that possibility, the results from the qualitative interviews indicate that, overall, the PEI symptom experience is similar in both 
Fig. 3 Pancreatic exocrine insufficiency (PEI) conceptual model

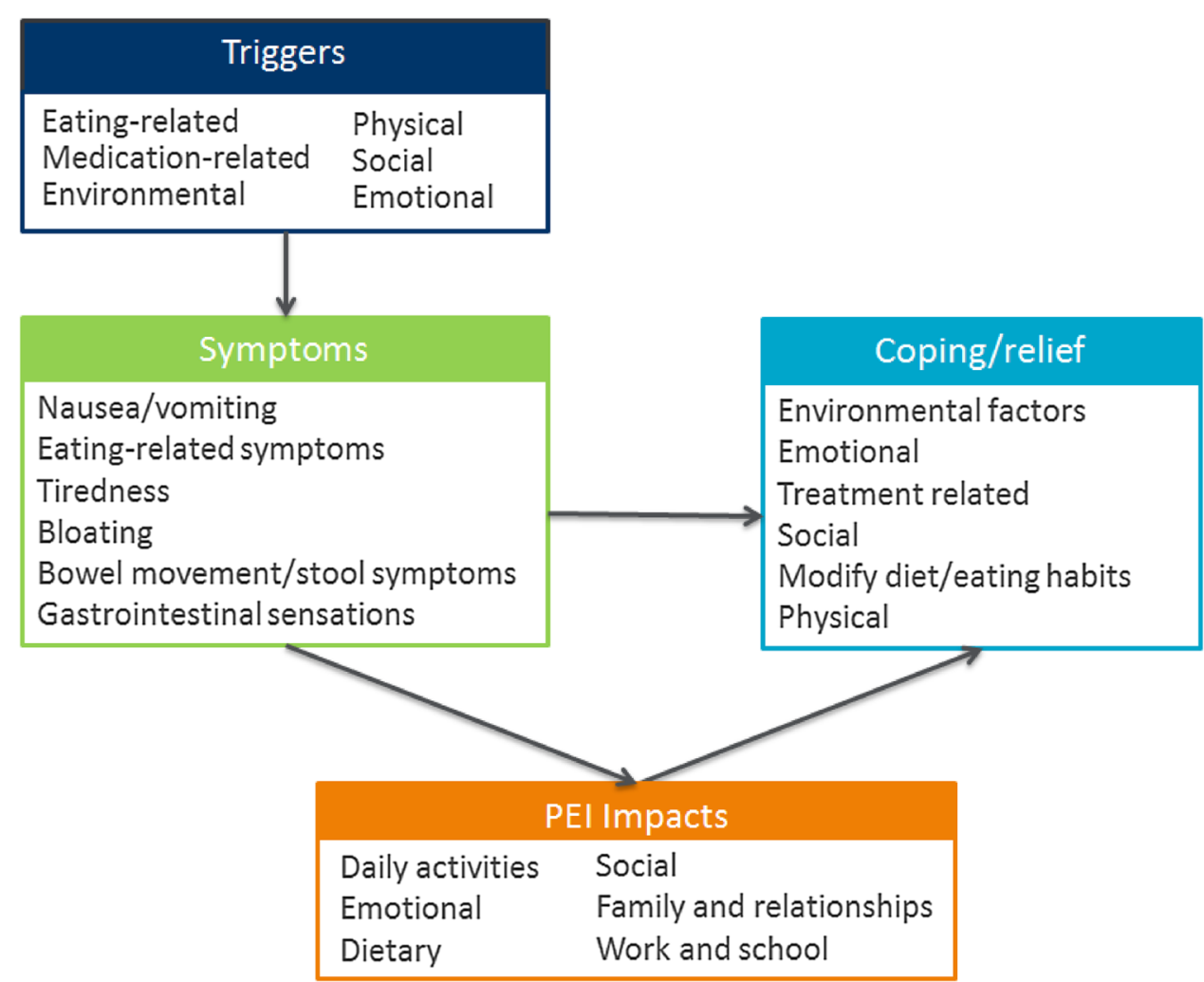

$\begin{array}{lccccc}\text { 1. In the past 7 days, did you have stomach } & \square_{0} & \square_{1} & \square_{2} & \square \text {, } \\ \text { pain (see the area circled below)? } & \text { No, not } & \text { Yes, a } & \text { Yes, } & \text { Yes, quite } & \text { Yes, a } \\ & \text { at all } & \text { little bit } & \text { some } & \text { a bit } & \text { lot } \\ & \text { Please go to } & \text { Puestion 3 } & \text { Please continue to question 2 }\end{array}$

9. In the past 7 days, did you feel the need to rush to the toilet to have a bowel movement (have a poo)?

$\begin{array}{ccccc}\square_{0} & \square_{1} & \square_{2} & \square_{3} & \square_{4} \\ \text { No, not } & \text { Yes, a } & \text { Yes, } & \text { Yes, quite } & \text { Yes, } \\ \text { at all } & \text { little bit } & \text { some } & \text { a bit } & \text { a lot }\end{array}$

18. In the past 7 days, did you avoid fatty food?

\begin{tabular}{|c|c|c|c|c|}
\hline$\square 0$ & $\square \square_{1}$ & $\square 2$ & $\square_{3}$ & $\square$. \\
\hline $\begin{array}{c}\text { No, not } \\
\text { at all }\end{array}$ & $\begin{array}{l}\text { Yes, a little } \\
\text { of the time }\end{array}$ & $\begin{array}{c}\text { Yes, } \\
\text { sometimes }\end{array}$ & $\begin{array}{c}\text { Yes, most } \\
\text { of the } \\
\text { time }\end{array}$ & $\begin{array}{l}\text { Yes, all of } \\
\text { the time }\end{array}$ \\
\hline
\end{tabular}

19. In the past 7 days, were your daily activities affected because of your enzyme problems?

$\begin{array}{ccccc}\square_{0} & \square_{1} & \square_{2} & \square_{3} & \square \\ \text { No, not } & \text { Yes, a } & \text { Yes, } & \text { Yes, quite } & \text { Yes, } \\ \text { at all } & \text { little bit } & \text { moderately } & \text { a bit } & \text { extremely }\end{array}$
20. In the past 7 days, did your enzyme problems affect your ability to concentrate?

$\begin{array}{ccccc}\square_{0} & \square_{1} & \square_{2} & \square_{3} & \square_{4} \\ \text { No, not } & \text { Yes, a } & \text { Yes, } & \text { Yes, most } & \text { Yes, all of } \\ \text { at all } & \begin{array}{c}\text { little of } \\ \text { the time }\end{array} & \text { sometimes } & \begin{array}{c}\text { of the } \\ \text { the time }\end{array} & \end{array}$

Fig. 4 Sample questions from the pancreatic exocrine insufficiency-specific patient-reported outcomes measure (PEI-Q) 
patient groups. This possibility will be further explored during quantitative validation of the PEI-Q, at which point it is expected that some items may be deleted if they do not appear equally relevant to patients with $\mathrm{CP}$ and those with $\mathrm{CF}$. Findings also identified that patients may have difficulty estimating correct enzyme doses, which could result in poor treatment adherence. The PEI-Q has the potential to help physicians identify the need to adjust treatment regimens, address dosing issues, and maintain treatment adherence, thus contributing to better outcomes for patients. The instrument may have particular value in PEI management following diagnosis or alongside existing diagnostic tests, providing supplementary information to physicians.

Our findings provide evidence that, in addition to direct effects on bowel function and digestive function, PEI symptoms also distress patients and interfere with daily activities. They can also result in patients avoiding foods that are difficult to digest rather than correctly adjusting doses of enzyme replacement. This may lead to malnutrition $[8,9,14,32]$ and worsening of malnutrition-related symptoms, which is associated with early mortality in patients with $\mathrm{CF}[8,9]$. Achieving adequate enzyme replacement is important for all of these conditions [14]. We believe the PEI-Q will assist physicians to assess the adequacy of PERT and should help improve the management of PEI symptoms.

Guidelines for PEI diagnosis and management in CP do not include PROs [33-35] but are reliant on stool elastase measurements, the only widely available test for PEI. Guidelines suggest that a trial period of PERT can clarify whether patients' symptoms are due to PEI [33, 34], but many physicians understand that responses to PERT vary widely. Additional symptoms found in our qualitative patient interviews highlight the benefit of a PRO to monitor PEI symptoms and the full patient experience. This will improve assessment of treatment response and will enable adjustment of PERT doses after consideration of patientreported severity of symptoms using a standardized measure.

It is well established that PROs can provide important endpoints for the evaluation of treatment benefits and adverse effects in clinical trials [16, 18]. In addition, Velikova et al. [36] provided evidence that use of a qualityof-life questionnaire in clinical practice can improve patient-doctor communication and can highlight symptoms previously untreated or discounted by the doctor and patient. The PEI-Q could help identify untreated symptoms, adjust enzyme-replacement doses to effective levels, and maintain good nutritional and general health status.

A strength of the study is that we included patients with $\mathrm{CF}$ and $\mathrm{CP}$, the two primary causes of PEI; thus, the findings provide evidence of content validity in different sub-groups. Inclusion of both patients with $\mathrm{CF}$ and those with $\mathrm{CP}$ maximized the likelihood of identifying symptoms and impacts that result from PEI rather than these comorbid conditions. It is still possible that some of the symptoms identified are due to $\mathrm{CP}$ or $\mathrm{CF}$, for example, epigastric pain. This will be further explored in a quantitative validation study that is already underway, and it is possible that some symptom concepts currently included may be deleted based on the findings of that study. Another strength of the study is that patients were recruited from three countries, ensuring findings have cross-cultural relevance.

However, the study has some limitations. Data were collected in France, Germany, and the UK only; further study in other countries and outside Europe would provide further confidence in the cross-cultural validity of the PEI-Q. That said, major differences are considered unlikely given that no differences were found across the countries studied. Another study limitation is that some patients' PEI was diagnosed by symptoms reported rather than laboratory-based tests, allowing the possibility that patients may not have been correctly diagnosed with PEI. This method was chosen to ensure feasibility and practicality of the study and also reflects clinical practice. Moreover, most participants were diagnosed using clinical tests such as the fecal elastase test, and no differences were identified in symptoms reported between patients diagnosed via different methods. However, we do recommend that future studies collect data from patients diagnosed using laboratory-based tests to cross-validate these findings.

This paper describes the first phase of development of the PEI-Q using qualitative interviews, ensuring the full patient experience is captured. Work thus far has been qualitative, leading to a list of symptom and impact concepts to document the comprehensive PEI symptom experience and the associated impact on patients' wellbeing. Symptoms and impacts identified have been integrated into the PEI-Q instrument. Quantitative testing of the psychometric validity and reliability of the instrument is necessary before it can be used in clinical practice $[37,38]$; the psychometric properties of the PEI-Q will be evaluated in a planned validation study.

\section{Conclusions}

This paper describes the development of a PEI-specific PRO instrument based on in-depth qualitative research of a diverse PEI patient sample. Data provide useful insights to improve understanding of the disease experience of patients with PEI and to better inform clinical management. 
Acknowledgements Mathias Schifflers was an employee at Abbott at the time this work was conducted and was involved in all aspects of the research. Chloe Tolley and Laura Maguire were employees at Adelphi Values and were involved in the conduct of interviews and qualitative analysis of the interview data. Caroline Jonquet was employed by Zeste Research and conducted the interviews in France. Sabine Bielfeldt, as an employee of Medical Market Research, conducted the patient interviews in Germany.

Author contributions Professors Johnson, Levy, Staab, and Lerch and Dr. Connett provided input into the study design, reviewed and provided interpretation of the literature review findings, and reviewed and provided clinical input into the qualitative study documents. They also provided review and interpretation of the qualitative results. Professor Dominguez-Munoz was involved in development of the PEI-Q, review of study documents, and providing clinical input and interpretation of the qualitative results. Mr. Arbuckle and Ms. Bonner and Williamson are employees of Adelphi Values, a health outcomes research company that was paid by Abbott to conduct the research. They were involved in all of the research activities, leading the study design, development of all study documents, and the analysis and write up of the data. All authors contributed to the writing of the manuscript and reviewed and approved the final manuscript.

\section{Compliance with Ethical Standards}

Funding This study was funded by Abbott.

Conflict of interest Mr. Arbuckle, Ms. Bonner, and Ms. Williamson were contracted by Abbott as consultants to perform the research. Professors Lerch, Levy, Johnson, and Dominguez-Munoz and Drs. Connett and Staab were engaged as expert scientific advisors by Adelphi Values on behalf of Abbott and received honoraria for their participation. The authors declare there are no other competing interests.

Open Access This article is distributed under the terms of the Creative Commons Attribution-NonCommercial 4.0 International License (http://creativecommons.org/licenses/by-nc/4.0/), which permits any noncommercial use, distribution, and reproduction in any medium, provided you give appropriate credit to the original author(s) and the source, provide a link to the Creative Commons license, and indicate if changes were made.

\section{References}

1. Toouli J, et al. Management of pancreatic exocrine insufficiency: Australasian Pancreatic Club recommendations. Med J Aust. 2010;193(8):461-7.

2. Messner JKV. Pancreatic enzyme therapy. Dtsch Arztebl Int. 2011;108:578-82.

3. Kahl S, et al. The effect of oral pancreatic enzyme supplementation on the course and outcome of acute pancreatitis: a randomized, double-blind parallel-group study. JOP. 2014;15(2):165-74.

4. Hernandez CA, Lerch MM. Sphincter stenosis and gallstone migration through the biliary tract. Lancet. 1993;341(8857):1371-3.

5. Keller J, Layer P. Human pancreatic exocrine response to nutrients in health and disease. Gut. 2005;54(Suppl 6):vi1-28.

6. Partelli S, et al. Faecal elastase-1 is an independent predictor of survival in advanced pancreatic cancer. Dig Liver Dis. 2012;44(11):945-51.
7. Garg PK, Tandon RK. Survey on chronic pancreatitis in the AsiaPacific region. J Gastroenterol Hepatol. 2004;19(9):998-1004.

8. Gaskin KJ. Nutritional care in children with cystic fibrosis: are our patients becoming better? Eur J Clin Nutr. 2013;67(5):558-64.

9. Sinaasappel M, et al. Nutrition in patients with cystic fibrosis: a European Consensus. J Cyst Fibros. 2002;1(2):51-75.

10. Fitzsimmons D, et al. Symptoms and quality of life in chronic pancreatitis assessed by structured interview and the EORTC QLQ-C30 and QLQ-PAN26. Am J Gastroenterol. 2005;100(4):918-26.

11. Mokrowiecka A, et al. Clinical, emotional and social factors associated with quality of life in chronic pancreatitis. Pancreatology. 2010;10(1):39-46.

12. Dominguez-Munoz JE, Iglesias-Garcia J. Oral pancreatic enzyme substitution therapy in chronic pancreatitis: is clinical response an appropriate marker for evaluation of therapeutic efficacy? JOP. 2010;11(2):158-62.

13. Sikkens EC, Cahen DL, van Eijck C, Kuipers EJ, Bruno MJ. Patients with exocrine insufficiency due to chronic pancreatitis are undertreated: a Dutch national survey. Pancreatology. 2012;12(1):71-3.

14. Sikkens EC, et al. Pancreatic enzyme replacement therapy in chronic pancreatitis. Best Pract Res Clin Gastroenterol. 2010;24(3):337-47.

15. Lasch KE, et al. PRO development: rigorous qualitative research as the crucial foundation. Qual Life Res. 2010;19(8):1087-96.

16. US Food and Drug Administration. Guidance for industry: patient reported outcome measures: use in medicinal product development to support labeling claims. Silver Spring, MD: US FDA; 2012.

17. Patrick DL, et al. Patient-reported outcomes to support medical product labeling claims: FDA perspective. Value Health. 2007;10(Suppl 2):S125-37.

18. European Medicines Agency. Reflection paper on the regulatory guidance for the use of health-related quality of life (HRQL) measures in the evaluation of medicinal products. London: EMA; 2009.

19. Fayers P, Bottomley AO. Quality of life research within the EORTC—-the EORTC QLQ-C30. Eur J Cancer. 2002;38:125-33.

20. Fitzsimmons D, et al. Development of a disease specific quality of life (QoL) questionnaire module to supplement the EORTC core cancer QoL questionnaire, the QLQ-C30 in patients with pancreatic cancer. EORTC Study Group on Quality of Life. Eur J Cancer. 1999;35(6):939-41.

21. Palesch YY, et al. Digestive disease quality of life instrument (DDQ-15): a validation study. Gastroenterology. 1998;114(Supple 1):A32-3.

22. Yount $\mathrm{S}$, et al. Assessment of patient-reported clinical outcome in pancreatic and other hepatobiliary cancers: the FACT Hepatobiliary Symptom Index. J Pain Symptom Manage. 2002;24(1):32-44.

23. Dimenas E, et al. Well-being and gastrointestinal symptoms among patients referred to endoscopy owing to suspected duodenal ulcer. Scand J Gastroenterol. 1995;30(11):1046-52.

24. Eypasch E, et al. Gastrointestinal quality of life index: development, validation and application of a new instrument. Br J Surg. 1995;82(2):216-22.

25. Guest G, Bunce A, Johnson L. How many interviews are enough? An experiment with data saturation and variability. Field Methods. 2006;18:59-82.

26. Glaser B, Strauss A. The constant comparative methods of qualitative analysis. In: Glaser BG, Strauss AL, editors. The discovery of grounded theory: strategies for qualitative research. New York: Aldine de Gruyter; 2010. p. 101-16. 
27. Atlas.ti software. ATLAS.ti Scientific Software Development GmbH. Berlin:Atlas;2013.

28. Willis GB. Cognitive interviewing: a tool for improving questionnaire design. Thousand Oaks: Sage Publications; 2004.

29. Perneger TV, et al. Sample size for pre-tests of questionnaires. Qual Life Res. 2015;24(1):147-51.

30. Patrick DL, et al. Content validity-establishing and reporting the evidence in newly developed patient-reported outcomes (PRO) instruments for medical product evaluation: ISPOR PRO Good Research Practices Task Force report: part 2-assessing respondent understanding. Value Health. 2011;14(8):978-88.

31. Abbott $\mathbf{J}$, et al. Ways of coping with cystic fibrosis: implications for treatment adherence. Disabil Rehabil. 2001;23(8):315-24.

32. Tan CS, et al. The relationship between nutritional status, inflammatory markers and survival in patients with advanced cancer: a prospective cohort study. Support Care Cancer. 2015;23(2):385-91.

33. Chronic Pancreatitis German Society of Digestive and metabolic diseases (DGVS), Hoffmeister A, Mayerle J, et al. S3-Consensus guidelines on definition, etiology, diagnosis and medical, endoscopic and surgical management of chronic pancreatitis German Society of Digestive and Metabolic Diseases (DGVS) [in German]. Z Gastroenterol. 2012;50(11):1176-224.

34. Mayerle $\mathrm{J}$, et al. Chronic pancreatitis-definition, etiology, investigation and treatment. Dtsch Arztebl Int. 2013;110(22):387-93.

35. Ellis I, Lerch MM, Whitcomb DC. Genetic testing for hereditary pancreatitis: guidelines for indications, counselling, consent and privacy issues. Pancreatology. 2001;1(5):405-15.

36. Velikova G, et al. Measuring Quality of Life in Routine Oncology Practice Improves Communication and Patient Well-Being: A Randomized Controlled Trial. J Clin Oncol. 2004;22(4):714-24.

37. Hays R, Anderson R, Reyiki DA. Assessing reliability and validity of measurement in clinical trials. In: Staquet MJ, Hays RD, Fayers PM, editors. Quality of life assessment in clinical trials. New York: Oxford University Press; 1998.

38. Aaronson $\mathrm{N}$, et al. Assessing health status and quality-of-life instruments: attributes and review criteria. Qual Life Res. 2002;11(3):193-205. 